\title{
O DIGITAL OBJECT IDENTIFIER (DOI) EM PERIÓDICOS CIENTÍFICOS ELETRÔNICOS DE COMUNICAÇÃO E INFORMAÇÃO
}

\author{
THE DIGITAL OBJECT IDENTIFIER (DOI) IN ELECTRONIC JOURNALS OF \\ COMMUNICATION AND INFORMATION
}

EL DIGITAL OBJECT IDENTIFIER (DOI) EN PERIÓDICOS CIENTÍFICOS ELECTRÓNICOS DE COMUNICACIÓN E INFORMACIÓN

'Erik André de Nazaré, ${ }^{2}$ Antônio Afonso Pereira Júnior, ${ }^{3}$ Carla Daniella Teixeira Girard, ${ }^{4}$ Cristiane Marina Teixeira Girard

${ }^{1}$ Universidade Federal do Pará, ${ }^{2}$ Universidade Federal de Minas Gerais, ${ }^{3}$ Universidade Federal Rural da Amazônia, ${ }^{4}$ Fundação Universidade Federal de Rondônia

\author{
Correspondência \\ 'Erik André de Nazaré \\ Universidade Federal do Pará \\ Belém, PA. \\ Email: eriknazare@hotmail.com \\ ORCID: http://orcid.org/0000-0003-3624-1992
}

Submetido em: 09-06-2017

Aceito em: 01-07-2017

Publicado: 12-07-2017

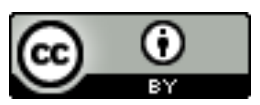

JITA: IF. Information transfer: protocols, formats,techniques. 
RESUMO: O presente estudo busca investigar a utilização do Digital Object Identifier (DOI) nos periódicos científicos de Biblioteconomia e Ciência da Informação e, proporcionando novas utilidades de integração com a Plataforma Lattes. Neste sentido, objetiva-se informar os títulos existentes em Biblioteconomia e Ciência da Informação em formato eletrônico, demonstrar a importância do DOI na integração com a Plataforma Lattes visando à garantia de credibilidade autoral e analisar as características das publicações que possuem DOI. A metodologia utilizada para o desenvolvimento deste estudo é bibliográfico, pesquisa com característica explicativa-descritiva. A partir do desenvolvimento da pesquisa, infere-se que de todos os periódicos analisados (33 periódicos), 10 títulos na avaliação de 2013 e 06 títulos da avaliação de 2014 apresentam o DOI em suas publicações, todas possuem classificação WebQualis, Qualis A1 na área de Comunicação e Informação. Em sua maioria as publicações são internacionais e apenas 3 títulos são nacionais. Torna-se necessário que os periódicos principalmente os nacionais acompanhem as novas tecnologias como o DOI para objetos e o ORCID para a identificação de pessoas, trazendo mais mecanismos que garantem credibilidade dos autores e para trazer conecção dos pesquisadores, e ambos já podem ser adotados na Plataforma Lattes.

PalavraS-Chave: Identificador de objeto digital. Biblioteconomia. Ciência da informação. Periódicos científicos.

\begin{abstract}
The present study seeks to investigate the use of the Digital Object Identifier (DOI) in the scientific journals of Communication and Information and, providing new integration utilities with the Lattes Platform. In this sense, it aims to inform the existing titles in Communication Information in electronic format, demonstrate the importance of DOI in the integration with the Lattes Platform in order to guarantee author credibility and analyze the characteristics of publications that have DOI. The methodology used for the development of this study is bibliographic, research with descriptive-descriptive characteristics. From the development of the research, it is inferred that of all the analyzed journals (33 journals), 10 titles in the evaluation of 2013 and 06 titles of the evaluation of 2014 present DOI in their publications, all have WebQualis classification, Qualis A1 in the area Communication and Information. Most publications are international and only 3 titles are national. It is necessary that journals, principally national ones, accompany new technologies such as DOI for objects and ORCID for the identification of people, bringing more mechanisms that guarantee authors 'credibility and to bring the researchers' connection, and both can already be adopted in the Platform Lattes.
\end{abstract}

KEYWORDS: Digital object identifier. Librarianship. Information science. Scientific journals.

RESUMEN: O presente estudo busca investigar el uso de Identificador de Objeto Digital (DOI) nos periódicos científicos de Biblioteconomía y Ciencia de la Información y proporcionando nuevas utilidades de integración con una Plataforma Lattes. En este sentido, la información se refiere a los títulos existentes en la Biblioteconomía y la Ciencia de la Información en formato electrónico, la demostración de la DOI en la integración con una Plataforma Lattes visando a la garantía de credibilidad de autor y etiquetar como características de las publicaciones que son DOI. Una metodología utilizada para el desarrollo de este estudio bibliográfico, la investigación con características explicativas-descritivas. (33 periódicos), 10 títulos en la evaluación de 2013 y 06 títulos de la evaluación de 2014, que se publican en el DOI en sus publicaciones, todas las clasificaciones WebQualis, Qualis A1 en el área De Comunicação e Información. En su mayoría como las publicaciones son los únicos 3 títulos están nacionales. Torna-se necesario que los periódicos también los países asociados como nuevas tecnologías como DOI para los objetos y ORCID para una identificación de personas, trazando más mecanismos que garantem credibilidad de los autores y para trazar conección de los buscadores na Plataforma Lattes.

Palabras Clave: Identificador de objeto digital. Biblioteconomia. Ciencia de la información. Periódicos científicos.

\begin{tabular}{l|l|}
$\mathrm{v} .15$ & $\mathrm{n} .3$
\end{tabular}

p.533-549

set./dez. 2017 


\section{INTRODUÇÃ̃o}

Sabe-se que o Digital Object Identifier (DOI) é um identificador que possibilita serviços de caráter complementar e que os metadados deste permite referenciar planos de identificação que utilizam deste identificador. Tendo em vista esta perspectiva, a temática deste estudo é estudar este identificador como disseminador da informação através dos periódicos científicos eletrônicos, principalmente os voltados ao âmbito da Comunicação e Informação.

Os periódicos científicos atuam na comunicação científica, através de informações científicas do que a comunidade produz enquanto conhecimento e avanço científico. Portanto, atuam como disseminadores de informações científicas.

Partindo desta premissa, faz-se necessários identificadores que permitam a busca pela informação de maneira eficiente e eficaz, já que vivemos uma era em que o tempo é bastante precioso. Assim, é desenvolvido o DOI como identificador e facilitador desta busca de informações de maneira mais veloz ao usuário. Mediante a isto, justifica-se este estudo.

Desta forma, questiona-se: o DOI enquanto identificador das publicações de Biblioteconomia e Ciência da Informação possibilitam novas utilidades de integração com a Plataforma Lattes? Para responder a esta indagação, pretende-se: a) informar os títulos existentes em Comunicação e Informação em formato eletrônico; b) demonstrar a importância do Digital Object Identifier na integração com a Plataforma Lattes visando a garantia de credibilidade autoral e; c) analisar as características das publicações que possuem o DOI. Com o objetivo geral de investigar a utilização do DOI nas publicações de Comunicação e Informação e, proporcionando novas utilidades de integração com a Plataforma Lattes e os específicos são: informar os títulos existentes na área já descrita em formato eletrônico; Demonstrar a importância do DOI na integração com a Plataforma Lattes visando à garantia de credibilidade autoral e Analisar as características das publicações que usam o DOI.

\section{REVISÃO DE LITERATURA}

$\mathrm{Na}$ composição da revisão de literatura, são abordados os seguintes assuntos: periódicos científicos, DOI e Plataforma Lattes, configurando dessa forma uma abordagem que a pesquisa traz no seu cerne.

\subsection{Periódicos científicos}

Abordar sobre o que norteia a comunicação científica acaba sendo consequentemente uma abordagem aos periódicos científicos, pois representam um veículo de suma importância 
na disseminação da informação científica e na evolução da ciência e tecnologia. Conforme Dias (2006, p. 51):

[...] os periódicos constituem um importante canal no âmbito da comunicação formal: em muitas áreas, como nas ciências naturais, exatas e da vida, são indubitavelmente o principal; em outras, como nas ciências sociais e humanas, dividem com os livros esse posto, sendo muitas vezes suplantado por esses [...].

A etimologia do termo "periódico" tem sua origem latina denominada de periodus, cujo significado representa espaço de tempo. Enquanto no latim originou-se da palavra publicatione, no qual é o ato ou efeito de publicar. Percebemos que o periódico foi idealizado para publicações de informações em uma freqüência regular (FACHIN; HILLESHEIM, 2006, p. 20).

Meadows (1999, p.8) suplementa esse sentido do termo periódico com a seguinte explanação:

[...] entrou em uso comum na segunda metade do século XVIII e se refere a qualquer publicação que apareça a intervalos determinados e contenha diversos artigos de diferentes autores. Para tornar ainda mais confusa à questão, a palavra serial [seriado ou publicação seriada] apareceu no século XIX para designar qualquer publicação editada em partes sucessivas e conexas. Em geral, journals (e magazines) são periódicos, mas principalmente em humanidades há publicações seriadas que desempenham muitas das funções de um jornal. Essas flutuações dos significados das palavras não são exclusivas da língua inglesa. Em alemão, por exemplo, os primeiros journals eram muitas vezes designados pela palavra Zeitung. Esta veio posteriormente a ser mais associada com jornais e, a partir do século XIX, a palavra Zeitschrift, passou a ser preferida nos títulos de revistas científicas.

Existem na literatura vários autores e instituições científicas que conceituam os periódicos, bem como a nomenclatura de publicações seriadas. Para a ABNT $(6021,2015)$ uma publicação periódica é aquela disponibilizada em qualquer suporte, com unidades sucessivas, designadas numericamente e/ou cronologicamente, visando ser produzida continuamente. Para evidenciar suas principais características e para diferenciação de outros tipos de materiais bibliográficos, a explanação conceitual de Campos (1980) abarca esta temática, conforme este autor:

Periódicos são publicações que geralmente se apresentam em fascículos ou brochuras, com freqüência regular, contendo vários assuntos, desde aqueles especializados até os de ordem geral, abrangendo uma publicação específica ou a população como um todo, sendo publicados de tempos em tempos, de forma periódica e por um período indeterminado.

Como esclarece Stumpf (1996) no século XIX, os periódicos são reconhecidos como meio de comunicação científica de credibilidade, consolidam-se como uma forma de registro da ciência. Pois, os custos e a demora na publicação de livros; troca de correspondências e atas não conseguiam sanar a necessidade de divulgar os resultados dos estudos científicos que emanavam nas comunidades acadêmicas. Resultando na união de cientistas para resolver 
este impasse e decidirem publicar suas pesquisas por partes, conjuntamente contando com a colaboração de diversos autores, provindo na publicação dos periódicos científicos.

Os primeiros periódicos de cunho científico surgiram em Paris com o título Journal dês Scavants, em 1965, e em Londres, surge o Philosophical Transactionsofthe Royal Societyof London, onde os membros da Royal Society divulgavam suas pesquisas. Estas duas publicações proviam informações sobre a ciência de forma constante, tendo por função resumir livros, fatos culturais, relatos de experimentos e observações científicas a fim de manter a sociedade européia informada, mas também cada uma apresentava características próprias (MEADOWS,1999).

Referente ao Brasil, posteriormente a fundação da Imprensa Régia em 1808, são editadas publicações relevantes para a sociedade e consta nos registros como precursores da publicação da ciência nacional, destacando-se o periódico a "gazeta médica do Rio de Janeiro", origina-se em 1862 e a "Gazeta médica da Bahia” publicado em 1866.

No século XIX e XX ocorreu à expansão da publicação de periódicos científicos, devido a diversos fatores como: crescimento do número de cientistas, de revistas científicas, publicações vinculadas com universidades, Estado e editoras comerciais; o avanço das Tecnologias da Comunicação e Informação (TIC's). Resultando no menor custo de editoração, na divulgação e disseminação de informação (FREITAS, 2006).

Todos esses elementos permitiram a evolução de forma de publicação científica demandando o formato eletrônico. Os trâmites no processo editorial e de publicação que ocorriam no meio físico também devem ser abrangidos no meio eletrônico, apesar do recurso online apresentar aspectos particulares vinculados ao suporte que contam com disponibilidade de acesso, resgate de informações, critérios de interatividade e navegabilidade. Mas devem seguir parâmetros balizados na tradição e legitimidade do periódico impresso: exibir política editorial, uma rigorosa revisão de qualidade (Peer Review), dedicar-se a uma área específica, manter edições regulares, ter ISSN, DOI, apresentar instruções aos autores, não ter caráter departamental para citar alguns. (GRUSZYNSKI, 2007).

\subsection{Digital Object Identification e a Plataforma Lattes}

De maneira geral, segundo o Brito $(2015$, p. 8) o DOI é "um sistema que permite a identificação, localização e descrição unívoca de entidades digitais - físicas ou abstratas”. Ou seja, este sistema visa a padronização e também uma forma de preservação das informações que encontram-se na internet. Complementando:

Um DOI é atribuído a um determinado conteúdo por um editor ou instituição responsável. Mesmo que se alterem as questões de direitos patrimoniais ou localização, o DOI deve permanecer o mesmo. Uma vez atribuído um DOI, não se

\begin{tabular}{l|l}
$\mathrm{v} .15$ & $\mathrm{n} .3$
\end{tabular}

p.533-549
set./dez. 2017 
pode removê-lo ou alterá-lo, mas é possível mudar as informações vinculadas a um DOI, fazendo um novo depósito de informações, mantendo o DOI e alterando os metadados (BRITO, 2015, p.8).

Tendo em vista esta perspectiva, Ferreira et al. (2015) aponta que o DOI é na verdade uma forma de padronização dos diversos documentos encontrados nas redes digitais. Assim sendo, normalmente tem sua composição de números e letras (ver Figura 1), onde é inserido em um objeto digital como uma maneira de identidade única no ambiente web.

\section{$\underbrace{10.1016 / j . u f u g .2010 .12 .004}$ prefixo: identifica o editor sufixo:
identifica o objeto digital}

Figura 1. Composição do DOI.

Fonte - http://www.icbas-ff.up.pt/biblioteca//images/pdf/9.pdf.

É relevante frisar a partir da figura acima que os números do DOI começam por “10”. Além do mais, seu prefixo e sufixo são separados pela barra (/). No que tange ao prefixo, pode-se afirmar que corresponde a número de 4 ou mais dígitos que estão vinculados a uma organização da editora, já o sufixo será viabilizado pela editora presente no prefixo, o qual cabe a ela determinar as regras de indetificação.

O DOI surgiu da ideia de 3 associações de cunho editorial, sendo elas International Publishers Association; International Association of Scientific, Tecnical and Medical Publishers; e, Association of American Publishers), assim, o objetivo geral destas instituições era de pensar uma alternativa que viabilizasse a grande demanda acarretada pelas TICs.

O gerenciamento de documentos no ciberespaço por meio do DOI foi inicialmente lançado na Feira Internacional do Livro, na Cidade de Frankfurt, na Alemanha, no ano de 1997 e atualmente é administrado pela The International DOI Foundation, Inc. (IDF). É um sistema de identificação numérico para conteúdo digital, que pode ser atribuído a artigos de periódicos, verbetes de enciclopédias, objetos de aprendizagem, imagens, livros eletrônicos ou conteúdos intelectuais que necessitem ter seus direitos de propriedade protegidos (SHITSUKA; SHITSUKA; RISEMBERG, 2016, p. 505).

Os autores supracitados expõem que o DOI não se limita apenas a artigos de revistas, porém, constata-se que seu universo abarca outros tipos de suportes, tais como os descritos na menção por eles acima. Sendo assim, pode-se discorrer que ao DOI cabe duas funções distintas, sendo elas melhor expostas na figura 2. 


\title{
duas funções do DOI
}

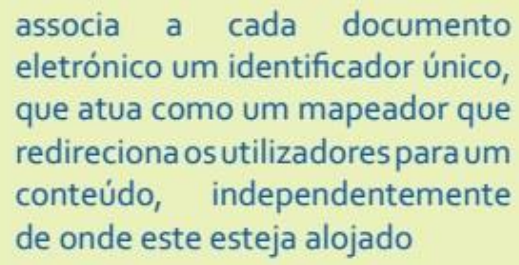

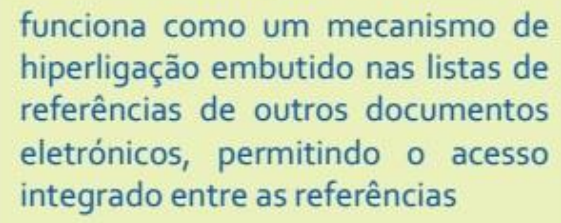

Figura 2 - Funções do DOI.

Fonte - http://www.icbas-ff.up.pt/biblioteca//images/pdf/9.pdf.

Pode-se afirmar, ainda, que o DOI opera mediante ao padrão de qualidade através da ISO 26324 (2012). De acordo com Brito (2015, p. 9), o DOI “[...] possibilita a atribuição de um identificador, denominado nome DOI, aliado ao depósito de metadados, para a posterior localização do objeto, por meio desse identificador. Com isso, é possível encontrar um recurso ou suas informações na web".

\begin{abstract}
Do ponto de vista de seus usuários, o sistema DOI opera em dois momentos distintos: depósito de metadados e resolução do nome DOI. No primeiro momento, o editor deposita os metadados associados aos objetos identificados pelos nomes DOI. Nessa etapa, os metadados são validados e processados por uma agência de registro - entre elas a Crossref - e, quando devidamente certificados, passam a constar no sistema DOI, no qual as agências de registro são federadas. No segundo momento, os leitores acionam um serviço de resolução de nomes tendo como parâmetro determinado nome DOI, o qual retornará o conjunto de metadados associados ao objeto identificado pelo mesmo. Esse tipo de acionamento ocorre de forma transparente ao se clicar em um link com nome DOI (BRITO, 2015, p. 10$11)$.
\end{abstract}

No âmbito de aplicação do DOI relacionado à Plataforma Lattes, Shitsuka, Shitsuka e Risemberg (2016, p. 505-506) afirmam que "[...] o código é utilizado pelo Conselho Nacional de Pesquisas (CNPq) na Plataforma Lattes para identificação de objetos digitalizados com copyright, como é o caso dos artigos cujos periódicos contém este gerenciador”.

De acordo com Ferreira (2015, p. 1), os principais erros para o preenchimento do DOI no Currículo Lattes são:

a) erros e/ou incompletudes no preenchimento dos metadados referentes ao nome do(s) autor(s) no periódico, por parte dos autores na hora da submissão e da equipe editorial na revisão;

\begin{tabular}{l|l} 
V.15 & n.3
\end{tabular}


b) incoerências entre o nome do autor cadastrado na Plataforma Lattes e na publicação que recebeu o DOI;

c) erro na inserção do DOI na Plataforma Lattes, pois os autores inserem, por exemplo, o $\quad$ endereço completo http://dx.doi.org/10.1590/S010039842002000100015, quando o correto é inserir dessa forma: 10.1590/S0100-39842002000100015.

No ano de 2007 o Conselho Nacional de Pesquisa (CNPq) realizou o contrato com a International Digital Obejct Identifier Foundation para utilização na Plataforma Lattes, do DOI este um instrumento de publicações nas redes sociais. Como todos os artigos da Coleção Scielo, assim como os periódicos do SEER já possuíam o DOI. A sua inserção no currículo lattes foi com a finalidade de certificação, proporcionando o acesso dos artigos pela plataforma, garantindo o direito autoral, trazendo maior credibilidade na informação registrada.(CNPq, 2007).

Para evidenciar a importância do Currículo Lattes no viés científico nacional, esclarece Balancieri et al (2005, p. 70):

[...] é o conjunto de sistemas de conhecimento da Plataforma Lattes, uma arquitetura de informações em CT\&I desenvolvida para o CNPq gerir suas atividades de fomento e para integrar em um mesmo ambiente os diversos atores ligados ao Sistema Nacional de Inovação do país. Além de viabilizar a interoperabilidade dos sistemas de informação das agências federais, a Plataforma Lattes tem racionalizado o processo de gestão de CT\& I.

Através desta explanação aludimos o quanto à implantação do DOI na Plataforma Lattes representa um avanço na evolução da comunicação científica. Pois estabelece uma ligação entre o currículo lattes e o site do artigo publicado. O DOI deve ser atribuído pela editora da publicação, esta informa o número DOI de cada artigo.

\section{METODOLOGIA}

O procedimento metodológico e operacional é abordado primeiramente de um estudo bibliográfico, segundo Forte (2006), esse tipo de pesquisa abrange o material que deve ser recolhido submetido a uma triagem, a partir da qual é possível estabelecer um plano de leitura delineado e conciso. A característica da pesquisa é do estilo explicativa-descritiva que na visão de Marconi e Lakatos (2010) esse tipo de pesquisa visa ampliar generalizações, estruturar e definir modelos teóricos, relacionar hipóteses em uma visão mais unitária do universo ou âmbito produtivo em geral e gerar hipóteses ou ideias por força de dedução lógica.

Realizou-se uma pesquisa no qual se utilizou como referência os dados extraídos da Plataforma Sucupira, extraindo os títulos de periódicos científicos da área de Comunicação e Informação que apresentaram classificação A1 nos anos de 2013 e 2014, visando demonstrar o DOI nas suas publicações. 
Neste sentido, foi necessário identificar os periódicos científicos na área de Comunicação e Informação, apresentando algumas características destes periódicos diante de informações encontradas no Catalogo Nacional de Publicações Seriadas (CCN) e no site do próprio periódico. Mostram as seguintes informações: Título, URL, periodicidade e outras descrições.

A metodologia trabalha com etapas a serem seguidas visando atingir uma finalidade na pesquisa. Conforme Marconi e Lakatos (2002, p. 15) a pesquisa “é um procedimento formal $[. .$.$] que requer um tratamento científico e se constitui no caminho para se conhecer a$ realidade que se pretende estudar".

A pesquisa configurou-se como bibliográfica, porque provem de material bibliográfico para compor o arcabouço teórico e subsidiar a fundamentação da comunicação científica como o trabalho de Meadows (1999) presente neste estudo.

O estudo caracteriza-se como explicativo-descritivo, no sentido explicativo pois preocupa- se em identificar na pesquisa fatores determinantes para a ocorrência de fenômenos (GIL, 2007), isto é, explica as coisas através dos resultados oferecidos. Também de forma descritiva porque pretende descrever os fatos e fenômenos de determinada realidade retratada. (TRIVIÑOS, 1987).

Inicialmente, identificaram-se os periódicos científicos publicados na área de Comunicação e Informação que estão nos indicados na avaliação da WebQualis de periódicos. Para tanto, pesquisou-se na plataforma sucupira, sites de busca, através de palavras-chave os títulos e links dos periódicos da área anteriormente mencionada, todos de cunho científico.

Vale salientar que estas publicações seriadas estão sendo publicados regularmente, e após a consulta em cada periódico e sites respectivos, realizou-se uma análise comparativa entre os dois anos de avaliação, indicando títulos que aparecem nos anos 2013 e 2014, assim como os títulos que desapareceram e outros que surgiram. E por último uma análise dos títulos que apresentaram o DOI em seus artigos científicos que traz a tona o foco deste estudo.

\section{ANÁLISE DE DADOS}

A partir da consulta na Plataforma Sucupira foi extraído e estruturado as informações que representam os títulos de periódicos que passaram pela avaliação do Qualis nos anos referente 2013 a 2014, na área de Comunicação e Informação, com extrato A1. Que representam um reconhecimento científico em âmbito nacional ter um extrato relevante para os títulos e os programas de pós-graduação.

Tornou-se necessário desmembrar por ordem crescente os anos de avaliações

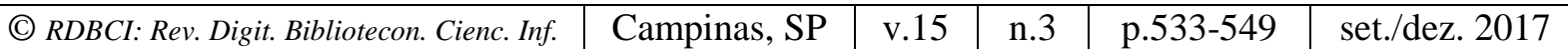


publicadas para demonstrar as suas especificidades e apontar o ano que passaram a adotar o DOI nas suas publicações. No Quadro 1, vemos os 17 títulos de periódicos da avaliação de 2013 e suas especificidades e a apresentação do ano encontrado o DOI em suas publicações.

QUADRO 1. Títulos na área de Comunicação e Informação como extrato A1 na avaliação de 2013.

\begin{tabular}{|c|c|}
\hline 2013 & DESCRIÇÃO \\
\hline $\begin{array}{l}\text { HERMÈS (PARIS. } \\
\text { 1988) }\end{array}$ & $\begin{array}{l}\text { Disponível online desde sua primeira publicação em 1988; País: França; periódico } \\
\text { quadrimestral ; DOI não localizado; url: http://irevues.inist.fr/ }\end{array}$ \\
\hline $\begin{array}{c}\text { INFORMAÇÃO \& } \\
\text { SOCIEDADE (UFPB. } \\
\text { ONLINE) }\end{array}$ & $\begin{array}{l}\text { Disponível online desde sua primeira publicação em 1991; País: Brasil; periódico } \\
\text { anual ; DOI não localizado; url: http://www.ies.ufpb.br/ojs2/index.php/ies/index }\end{array}$ \\
\hline $\begin{array}{c}\text { INTERNATIONAL } \\
\text { JOURNAL OF } \\
\text { COMMUNICATION } \\
\text { (ONLINE) }\end{array}$ & $\begin{array}{l}\text { Disponível online desde sua primeira publicação em 2007; País: USA; periódico } \\
\text { anual; DOI não localizado; url: http://ijoc.org/index.php/ijoc/index }\end{array}$ \\
\hline $\begin{array}{l}\text { INVESTIGACIÓN } \\
\text { BIBLIOTECOLÓGICA }\end{array}$ & $\begin{array}{l}\text { Disponível online desde sua primeira publicação em } 1986 \text {; País: México; } \\
\text { periódico semestral; DOI desde 2017; url: http://iibi.unam.mx/revistaCuib.html }\end{array}$ \\
\hline $\begin{array}{l}\text { JOURNALISM } \\
\text { STUDIES }\end{array}$ & $\begin{array}{l}\text { Disponível online desde } 2000 \text {; País: México; periódico semestral; DOI em 2000; } \\
\text { url: http://www.tandfonline.com/toc/rjos20/current }\end{array}$ \\
\hline $\begin{array}{l}\text { KNOWLEDGE } \\
\text { ORGANIZATION }\end{array}$ & $\begin{array}{l}\text { Disponível online desde } 1974 \text {; País: Alemanha; periódico trimestral; DOI não foi } \\
\text { possível a identificação ; url: http://www.isko.org/ko.html }\end{array}$ \\
\hline $\begin{array}{l}\text { MEDIA, CULTURE \& } \\
\text { SOCIETY }\end{array}$ & $\begin{array}{l}\text { Disponível online desde } 1979 \text {; País: Inglaterra; periódico trimestral; DOI desde } \\
2004 \text {; url: http://journals.sagepub.com/home/mcs }\end{array}$ \\
\hline $\begin{array}{c}\text { PERSPECTIVAS EM } \\
\text { CIÊNCIA DA } \\
\text { INFORMAÇÃO } \\
\text { (IMPRESSO) }\end{array}$ & País: Brasil; periódico semestral; \\
\hline $\begin{array}{c}\text { PERSPECTIVAS EM } \\
\text { CIÊNCIA DA } \\
\text { INFORMAÇÃO } \\
\text { (ONLINE) }\end{array}$ & $\begin{array}{l}\text { Disponível online desde } 1996 \text {; País: Brasil; periódico semestral; DOI não } \\
\text { localizado ; url: http://portaldeperiodicos.eci.ufmg.br/index.php/pci }\end{array}$ \\
\hline $\begin{array}{l}\text { REVISTA ESPAÑOLA } \\
\text { DE } \\
\text { DOCUMENTACIÓN } \\
\text { CIENTÍFICA }\end{array}$ & $\begin{array}{l}\text { Disponível online desde } 1998 \text {; País: Espanha; periódico trimestral; DOI desde } \\
2008 \text {; url: http://redc.revistas.csic.es/index.php/redc/index }\end{array}$ \\
\hline $\begin{array}{l}\text { SCIENTOMETRICS } \\
\text { (PRINT) }\end{array}$ & $\begin{array}{l}\text { Disponível online desde sua primeira publicação em } 1978 \text {; País: } \\
\text { periódico } \quad \text { bimestral; } \quad \text { DOI } \quad \text { desde } 2007 \text {; } \\
\text { https://link.springer.com/journal/volumesAndIssues/11192 }\end{array}$ \\
\hline SOCIAL SEMIOTICS & $\begin{array}{l}\text { Disponível online desde } 1991 \text {; País: USA; periódico Trimestral; DOI desde } 2001 \text {; } \\
\text { url: http://www.tandfonline.com/toc/csos20/current }\end{array}$ \\
\hline SOCIÉTÉS (PARIS) & $\begin{array}{l}\text { Disponível online desde } 2001 \text {; País: França; periódico semestral; DOI desde } 2001 \\
\text {; url: https://www.cairn.info/revue-societes.htm }\end{array}$ \\
\hline $\begin{array}{l}\text { STUDIES IN HISTORY } \\
\text { AND PHILOSOPHY } \\
\text { OF SCIENCE }\end{array}$ & $\begin{array}{l}\text { Disponível online desde } 1995 \text {; País: USA; periódico trimestral; DOI desde } 1995 \text {; } \\
\text { url: https://www.journals.elsevier.com/studies-in-history-and-philosophy-of- } \\
\text { science-part-a/ }\end{array}$ \\
\hline
\end{tabular}




\begin{tabular}{|c|l|}
\hline $\begin{array}{c}\text { TELEVISION \& NEW } \\
\text { MEDIA }\end{array}$ & $\begin{array}{l}\text { Disponível online desde } 2000 \text {; País: USA; periódico bimestral; DOI desde } 2010 ; \\
\text { url: https://www.journals.elsevier.com/studies-in-history-and-philosophy-of- } \\
\text { science-part-a/ }\end{array}$ \\
\hline TRANSINFORMAÇÃO & $\begin{array}{l}\text { Disponível online desde } 1997 \text {; País: Brasil; periódico quadrimestral; DOI desde } \\
2014 ; \text { url: https://www.journals.elsevier.com/studies-in-history-and-philosophy-of- } \\
\text { science-part-a/ }\end{array}$ \\
\hline
\end{tabular}

Fonte: Adaptação dos autores com base nas informações da WebQualis, Portal de Periódicos CAPES, CCN e site do Periódico.

No total de 17 títulos de periódicos de Comunicação e Informação, com extrato A1 na avaliação de 2013, desse universo analisado 12 títulos são de origem internacional, principalmente dos Estados Unidos e, sendo 5 títulos nacionais.

Percebemos também que entre todos os títulos analisados, apenas 10 apresentam o DOI em suas publicações, não foi possível localizar o DOI nos periódicos Hermés, Informação \& sociedade, International Journal of Communication, Knowledge organization e perspectivas em Ciência da Informação, por não apresentarem elou por ter acesso limitado ao periódico. E no caso, do periódico Perspectivas em Ciência da Informação no formato impresso indicado também na avaliação, por esse tipo de formato não é possível ter o DOI, então não foi incluído dentro da análise por essa característica.

QUADRO 2. Títulos na área de Comunicação e Informação como extrato A1 na avaliação de 2014.

\begin{tabular}{|c|c|}
\hline 2014 & DESCRIÇÃO \\
\hline $\begin{array}{l}\text { COMUNICAR } \\
\text { (HUELVA) }\end{array}$ & País: Espanha; periódico quadrimestral; \\
\hline $\begin{array}{l}\text { COMUNICAR } \\
\text { (HUELVA. } \\
\text { INTERNET) }\end{array}$ & $\begin{array}{l}\text { Disponível online desde sua primeira publicação em } 1993 \text {; País: Espanha; } \\
\text { periódico } \quad \text { quadrimestral } \quad \text {; DOI desde } \\
\text { https://www.revistacomunicar.com/index.php?\&idioma=en }\end{array}$ \\
\hline $\begin{array}{l}\text { EL PROFESIONAL DE } \\
\text { LA INFORMACIÓN }\end{array}$ & $\begin{array}{l}\text { Disponível online desde ; País: Espanha; periódico bimestral ; DOI não } \\
\text { localizado; url: http://www.elprofesionaldelainformacion.com/index.html }\end{array}$ \\
\hline $\begin{array}{l}\text { HERMĖS (PARIS. } \\
\text { 1988) }\end{array}$ & $\begin{array}{l}\text { Disponível online desde sua primeira publicação em 1988; País: França; periódico } \\
\text { quadrimestral ; DOI não localizado; url: http://irevues.inist.fr/ }\end{array}$ \\
\hline $\begin{array}{l}\text { INFORMAÇÃO \& } \\
\text { SOCIEDADE (UFPB. } \\
\text { IMPRESSO) }\end{array}$ & País: Brasil; periódico anual \\
\hline $\begin{array}{l}\text { INFORMAÇÃO \& } \\
\text { SOCIEDADE (UFPB. } \\
\text { ONLINE) }\end{array}$ & $\begin{array}{l}\text { Disponível online desde sua primeira publicação em 1991; País: Brasil; periódico } \\
\text { anual ; DOI não localizado; url: http://www.ies.ufpb.br/ojs2/index.php/ies/index }\end{array}$ \\
\hline $\begin{array}{l}\text { INFORMATION } \\
\text { RESEARCH }\end{array}$ & $\begin{array}{l}\text { Disponível online desde sua primeira publicação em 1995; País: Suécia; periódico } \\
\text { trimestral; DOI não localizado; url: http://www.informationr.net/ir/ }\end{array}$ \\
\hline $\begin{array}{l}\text { INFORMATION } \\
\text { SCIENCES }\end{array}$ & $\begin{array}{l}\text { Disponível online desde sua primeira publicação em } 1968 \text { País: USA; } \\
\text { periodicidade } 3 \text { vezes na semana ; DOI colocado para todos os volumes a partir de } \\
\text { 1968; url: http://www.sciencedirect.com/science/journal/00200255 }\end{array}$ \\
\hline $\begin{array}{l}\text { INTERNATIONAL } \\
\text { JOURNAL OF } \\
\text { COMMUNICATION }\end{array}$ & $\begin{array}{l}\text { Disponível online desde sua primeira publicação em 2007; País: USA; periódico } \\
\text { anual; DOI não localizado; url: http://ijoc.org/index.php/ijoc/index. }\end{array}$ \\
\hline
\end{tabular}




\begin{tabular}{|c|c|}
\hline (ONLINE) & \\
\hline $\begin{array}{c}\text { INVESTIGACIÓN } \\
\text { BIBLIOTECOLÓGICA }\end{array}$ & $\begin{array}{l}\text { Disponível online desde sua primeira publicação em } 1986 \text {; País: México; } \\
\text { periódico semestral; DOI desde 2017; url: http://iibi.unam.mx/revistaCuib.html }\end{array}$ \\
\hline $\begin{array}{c}\text { JOURNAL OF THE } \\
\text { AMERICAN SOCIETY } \\
\text { FOR INFORMATION } \\
\text { SCIENCE AND } \\
\text { TECHNOLOGY } \\
\text { (ONLINE) }\end{array}$ & $\begin{array}{l}\text { Disponível online desde sua primeira publicação em } 1950 \text { ( periódicos que é } \\
\text { continuação de outras publicações); País: USA; periódico mensal; DOI colocado } \\
\text { para todos os volumes a partir de } 1968 \text {; url: } \\
\text { http://onlinelibrary.wiley.com/journal/10.1002/\%28ISSN\%292330-1643/issues }\end{array}$ \\
\hline $\begin{array}{l}\text { KNOWLEDGE } \\
\text { ORGANIZATION }\end{array}$ & $\begin{array}{l}\text { Disponível online desde } 1974 \text {; País: Alemanha; periódico trimestral; DOI não foi } \\
\text { possível a identificação ; url: http://www.isko.org/ko.html }\end{array}$ \\
\hline $\begin{array}{l}\text { PERSPECTIVAS EM } \\
\text { CIÊNCIA DA } \\
\text { INFORMAÇÃO } \\
\text { (ONLINE) }\end{array}$ & $\begin{array}{l}\text { Disponível online desde } 1996 \text {; País: Brasil; periódico semestral; DOI não } \\
\text { localizado ; url: http://portaldeperiodicos.eci.ufmg.br/index.php/pci }\end{array}$ \\
\hline $\begin{array}{l}\text { REVISTA ESPAÑOLA } \\
\text { DE } \\
\text { DOCUMENTACIÓN } \\
\text { CIENTÍFICA }\end{array}$ & $\begin{array}{l}\text { Disponível online desde } 1998 \text {; País: Espanha; periódico trimestral; DOI desde } \\
2008 \text {; url: http://redc.revistas.csic.es/index.php/redc/index }\end{array}$ \\
\hline SOCIÉTÉS (PARIS) & $\begin{array}{l}\text { Disponível online desde } 2001 \text {; País: França; periódico semestral; DOI desde } 2001 \\
\text {; url: https://www.cairn.info/revue-societes.htm }\end{array}$ \\
\hline TRANSINFORMAÇÃO & $\begin{array}{l}\text { Disponível online desde } 1997 \text {; País: Brasil; periódico quadrimestral; DOI desde } \\
2014 \text {; url: https://www.journals.elsevier.com/studies-in-history-and-philosophy-of- } \\
\text { science-part-a/ }\end{array}$ \\
\hline
\end{tabular}

Fonte: Adaptação dos autores com base nas informações da WebQualis, Portal de Periódicos CAPES, CCN e site do Periódico.

No total de 16 títulos de periódicos de Comunicação e Informação, com extrato A1 na avaliação de 2014, desse universo analisado foram identificadas 7 nacionalidades e 12 títulos são de origem internacional, principalmente da Espanha e Estados Unidos e, sendo 4 títulos nacionais.

Dos títulos analisados, apenas 7 títulos apresentam o DOI em suas publicações, não foi possível localizar o DOI nos periódicos El Professional de la información, Hermés, Informação \& Sociedade, Information research, International Journal of Communication, Knowledge Organization, Perspectivas em Ciência da Informação. Nos casos, dos periódicos Comunicar e Informação \& Sociedade indicados no formato impresso demonstrado na avaliação, por esse tipo de formato não ser possível a obtenção do DOI, então não foi incluso dentro da análise por essa característica.

No quadro a seguir, demonstra a relação dos títulos diante desses dois anos de avaliação do Qualis para periódicos da Comunicação e Informação. 
QUADRO 3. Títulos na área de Comunicação e Informação como extrato A1.

\begin{tabular}{|c|c|c|c|}
\hline 2013 & $\begin{array}{l}\text { POSSUI } \\
\text { DOI? }\end{array}$ & 2014 & POSSUI DOI? \\
\hline HERMÈS (PARIS. 1988) & NÃO & COMUNICAR (HUELVA) & NÃO \\
\hline $\begin{array}{c}\text { INFORMAÇÃO \& } \\
\text { SOCIEDADE (UFPB. } \\
\text { ONLINE) }\end{array}$ & NÃO & $\begin{array}{l}\text { COMUNICAR (HUELVA. } \\
\text { INTERNET) }\end{array}$ & SIM \\
\hline $\begin{array}{l}\text { INTERNATIONAL } \\
\text { JOURNAL OF } \\
\text { COMMUNICATION } \\
\text { (ONLINE) }\end{array}$ & NÃO & $\begin{array}{l}\text { EL PROFESIONAL DE LA } \\
\text { INFORMACIÓN }\end{array}$ & NÃO \\
\hline $\begin{array}{c}\text { INVESTIGACIÓN } \\
\text { BIBLIOTECOLÓGICA }\end{array}$ & SIM & HERMÈS (PARIS. 1988) & NÃO \\
\hline JOURNALISM STUDIES & SIM & $\begin{array}{l}\text { INFORMAÇÃO \& } \\
\text { SOCIEDADE (UFPB. } \\
\text { IMPRESSO) }\end{array}$ & NÃO \\
\hline $\begin{array}{l}\text { KNOWLEDGE } \\
\text { ORGANIZATION }\end{array}$ & NÃO & $\begin{array}{l}\text { INFORMAÇÃO \& } \\
\text { SOCIEDADE (UFPB. } \\
\text { ONLINE) }\end{array}$ & NÃO \\
\hline $\begin{array}{l}\text { MEDIA, CULTURE \& } \\
\text { SOCIETY }\end{array}$ & SIM & INFORMATION RESEARCH & NÃO \\
\hline $\begin{array}{c}\text { PERSPECTIVAS EM } \\
\text { CIÊNCIA DA } \\
\text { INFORMAÇÃO (IMPRESSO) }\end{array}$ & NÃO & INFORMATION SCIENCES & SIM \\
\hline $\begin{array}{c}\text { PERSPECTIVAS EM } \\
\text { CIÊNCIA DA } \\
\text { INFORMAÇÃO (ONLINE) }\end{array}$ & NÃO & $\begin{array}{l}\text { INTERNATIONAL } \\
\text { JOURNAL OF } \\
\text { COMMUNICATION } \\
\text { (ONLINE) }\end{array}$ & NÃO \\
\hline $\begin{array}{l}\text { REVISTA ESPAÑOLA DE } \\
\text { DOCUMENTACIÓN } \\
\text { CIENTÍFICA }\end{array}$ & SIM & $\begin{array}{l}\text { INVESTIGACIÓN } \\
\text { BIBLIOTECOLÓGICA }\end{array}$ & SIM \\
\hline SCIENTOMETRICS (PRINT) & SIM & $\begin{array}{c}\text { JOURNAL OF THE } \\
\text { AMERICAN SOCIETY FOR } \\
\text { INFORMATION SCIENCE } \\
\text { AND TECHNOLOGY } \\
\text { (ONLINE) }\end{array}$ & SIM \\
\hline SOCIAL SEMIOTICS & SIM & $\begin{array}{l}\text { KNOWLEDGE } \\
\text { ORGANIZATION }\end{array}$ & NÃO \\
\hline SOCIÉTÉS (PARIS) & SIM & $\begin{array}{c}\text { PERSPECTIVAS EM } \\
\text { CIÊNCIA DA INFORMAÇÃO } \\
\text { (ONLINE) }\end{array}$ & NÃO \\
\hline $\begin{array}{l}\text { STUDIES IN HISTORY AND } \\
\text { PHILOSOPHY OF SCIENCE }\end{array}$ & SIM & $\begin{array}{c}\text { REVISTA ESPAÑOLA DE } \\
\text { DOCUMENTACIÓN }\end{array}$ & SIM \\
\hline
\end{tabular}




\begin{tabular}{|c|c|c|c|}
\hline & & CIENTÍFICA & SIM \\
\hline $\begin{array}{c}\text { TELEVISION \& NEW } \\
\text { MEDIA }\end{array}$ & SIM & SOCIÉTÉS (PARIS) & SIM \\
\hline TRANSINFORMAÇÃO & SIM & TRANSINFORMAÇÃO & ÇOPES, \\
\hline
\end{tabular}

Fonte: Adaptação dos autores com base nas informações da WebQualis, Portal de Periódicos CAPES, CCN e site do Periódico.

Na relação entre os títulos referente as avaliações de 2013 e 2014. Nota-se que alguns títulos da área de comunicação e informação com a classificação A1, no universo de 33 títulos, sendo que 09 títulos aparecem em ambas as avaliações, que são: Hermés, Informação \& Sociedade, International Journal of Communication, Investigacion Bibliotecológica, Knowledge Organization, Perspectivas em Ciência da Informação, Revista Española de Documentacion Cientifica, Sociétés e Transinformação. Dentro esses periódicos 5 não possuem o DOI em suas publicações, que são: Perspectivas em Ciência da Informação; Knowledge Organization; Internation Journal of Communication; Informação \& Sociedade e Hermés.

Sendo, então desse universo de 33 títulos, 05 títulos novos aparecem na avaliação de 2014, que são: Journal of the American Society for Information Science and Tecnology, Information Sciences, Information Research, El professional de La Informacion, Comunicar. Considerando os títulos repetidos apenas uma vez. Entre esses 05 periódicos apenas 03 apresentam o DOI em seus artigos, que são: Comunicar; Information Sciences; Journal of the American Society for Information Science and Tecnology.

Continuando as comparações das avaliações de 2013 e 2014, 05 títulos deixaram de aparecer com a classificação A1 em 2014 e estavam presentes em 2013, que são: Television \& New Media; Social Semiotics; Scientometrics; Media, Culture \& Society e Journalism Studies. Sendo que todos esses 5 periódicos apresentam DOI em suas publicações. Outros requisitos foram levados em conta para que os mesmos não constassem na relação de 2014.

No ano de 2013, dos 17 títulos, apenas 10 apresentam de fato o DOI em suas publicações e, no qual 09 são periódicos internacionais e apenas 01 tem origem brasileira, que é o Transinformação.

Referente ao DOI, nas avaliações de 2013 e 2014, neste prisma 12 títulos possuem o DOI em artigos científicos, e levando em consideração a avaliação mais atual de 2014 somente 6 apresentam o DOI. Nota-se que alguns títulos se repetem e também por entrarem na avaliação a versão impressa não tem como terem o DOI em suas publicações. Os periódicos nacionais que aparecem em 2014, que são: informação \& sociedade e Perspectivas da Ciência da Informação não apresentam o DOI em suas publicações, possivelmente pôr no país a adoção do DOI em artigos é algo bem recente no campo científico e, aparecendo nos currículos lattes dos pesquisadores e esbarra também nos aspectos financeiros. 
O DOI possivelmente vai ser tornando cada vez mais evidente nas publicações em nível nacional elou internacional, acredita-se que nas próximas avaliações os títulos presentes na relação, devem apresentar o DOI. Pois, este tornou-se um importante mecanismo para identificações das publicações e da evidência científica.

\section{CONSIDERAÇÕES FINAIS}

Na literatura percebemos que em relação à comunicação científica, as novas TIC'S e criação de outros mecanismos computacionais trouxeram uma evolução na produção e disseminação de pesquisas científicas. Evidenciando no arcabouço teórico, as primeiras formas básicas de comunicação até o amadurecimento e implantação dos periódicos no âmbito científico. Este veículo, tanto no formato impresso como eletrônico, garantiu o engrandecimento da Ciência e reconhecimento dos autores.

Neste estudo apontamos o incremento do DOI nas publicações seriadas como forma de credibilidade de informações científicas e garantia dos direitos autorais, como este se tornou um elemento de identificação crucial no fornecimento e integração de dados, que foi aderido na Plataforma Lattes, permitindo que no acesso de um artigo científico e/ou no currículo lattes tenha uma numeração de identificação que estar presente no periódico no qual o artigo fora publicado.

Com o intuito de conhecer os periódicos da área de Comunicação e Informação que tenham o DOI, pesquisou-se e encontramos um universo de 17 publicações seriadas na avaliação de 2013 e 16 títulos de periódicos referente ao ano de 2014, todos com avaliação Qualis A1. Mas, tornou-se evidente por este estudo que a avaliação de 2014 demonstrou que apenas 06 títulos internacionais apresentam o DOI em suas publicações, sabendo-se que foi desconsideradas as publicações seriadas indicadas com o formato impresso e os títulos que se repetiam foram considerados apenas uma vez. Apenas dois periódicos brasileiros estão presentes no ano de 2014 e os mesmos não possuem DOI, podem está demonstrando os entraves que a publicação científica nacional enfrenta, mas que possivelmente cada vez vai crescendo exponencialmente as publicações com ferramentas digitais como o DOI.

Este estudo proporciona a verificação da área de Comunicação e informação nesta interação de dados, e busca elucidar a importância do reconhecimento de suas contribuições nas pesquisas científicas bem como dos seus autores. Pois, torna-se necessário que os periódicos principalmente nacional acompanhe as novas tecnologias como o DOI para objetos e o ORCID para a identificação de pessoas, trazendo mais mecanismos que garantem credibilidade dos autores e para trazer conecção dos pesquisadores, e ambos já podem ser adotados na Plataforma Lattes. Trazendo à tona novas veredas para evolução da Ciência e formação de novos conhecimentos. 


\section{REFERÊNCIAS}

ASSOCIAÇÃO BRASILEIRA DE NORMAS TÉCNICAS. NBR 6021: Informação e documentação- publicação periódica técnica e/ou científica-Apresentação. Rio de Janeiro: ABNT, 2015.

BALANCIERI, Renato et al. A análise de redes de colaboração científica sob as novas tecnologias de informação e comunicação: um estudo na Plataforma Lattes. Ciência da Informação, Brasília, DF, v.34, n.1, p. 64-77, jan. /abr. 2015. Disponível em: < http://www.scielo.br/scielo.php?pid=s010019652005000100008\&script=sci_abstract\&tlng=pt $>$.

Acesso em: 10 abr. 2016.

BRITO, Ronnie Fagundes de. Guia do usuário do Digital Object Identifier. Brasília, DF: IBICT, 2015.

CAMPOS, Liene. Publicações periódicas e seriadas. 1980. 173f. Dissertação (Mestrado em Biblioteconomia) - Pontifícia Universidade Católica de Campinas, Campinas, 1980.

CONSELHO NACIONAL DE PESQUISA (CNPq). Plataforma Lattes usará certificação DOI para artigos publicados. Brasília: CNPQ, 2007. Disponível em: < http://cvirtual-ccs.bvsalud.org/tikiread_article.php?articleId=162\&highlight=automatic $>$. Acesso em: 10 abr. 2016.

DIAS, Carolina Guimarães de Souza. Periódicos na comunicação científica: produção e difusão de periódicos e panorama dos veículos brasileiros da área de comunicação na base Qualis. 2006. 171f. Dissertação (Mestrado em Comunicação e cultura) - Escola de Comunicação da Universidade Federal do Rio de Janeiro, Rio de Janeiro, 2006.

FACHIN, Gleisy Regina Bóries; HILLESHEIM, Araci Isaltina de Andrade. Periódico científico: padronizado e organizado. Florianópolis: editora UFSC, 2006.

FORTE, Sérgio Henrique Arruda Cavalcante. Manual de elaboração de tese, dissertação e monografia. Fortaleza: Universidade de Fortaleza, 2006.

FREITAS, Maria Helena. Considerações acerca dos primeiros periódicos científicos brasileiros. Ciência da Informação, Brasília, DF, v. 35, n. 3, p. 54-66, set/dez. 2006. Disponível em: 〈http:/www.scielo.br/pdf/ci/v35n3a06.pdf〉. Acesso em: 15 mar. 2016.

GIL, Antonio Carlos. Métodos e técnicas de pesquisa social. 6 ed. São Paulo: Atlas, 2007.

GRUSZYNSKI, Ana Cláudia; SANSEVERINO, Antônio. O Periódico na área de humanidades: critérios de avaliação. In: CONGRESSO BRASILEIRO DE CIENCIAS DA COMUNICAÇÃO, 28., Rio de Janeiro. Anais eletrônicos... Rio de Janeiro, 2005. Disponívelem: $<$ http./www.portcom.intercom.org.br/pdfs/4753337232488045223286711146801073 9789.pdf $>$. Acesso em: 20 mar. 2016. 
INSTITUTO BRASILEIRO DE INFORMAÇÃO EM CIÊNCIA E TECNOLOGIA. Portal do Sistema Eletrônico de Editoração de Revistas: SEER. Disponível em: 〈http://seer.ibict.br/>. Acesso em: 20 jan. 2016.

MARCONI, Marina de Andrade; LAKATOS, Eva Maria. Fundamentos de metodologia científica.7. ed. São Paulo: Atlas, 2010.

MARCONI, Marina de Andrade; LAKATOS, Eva Maria. Técnicas de pesquisa. 5 ed. ampl. São Paulo: Atlas, 2002.

MEADOWS, Arthur Jack. A comunicação científica. Brasília, DF: Briquet de Lemos/Livros, [c1999].

SHITSUKA, Ricardo; SHITSUKA, Dorlivete Moreira; RISEMBERG, Rabbin Ive Carolina Shitsuka. Avaliação das noções de Digital Object Identifier em alunos de um Curso de PósGraduação. Inf. Inf., Londrina, v. 21, n. 1, p. 496-519, jan./abr. 2016.

STUMPF, Ilda Regina Chico. Passado e futuro das revistas científicas. Ciência da Informação, Brasília, DF, v.25, n. 3, p.383-386, set. /dez. 1996. Disponível em: $\langle$ http $/ /$ seer.ufrgs.br/intexto/article/view/3369/3953 $>$. Acesso em: 15 mar. 2016.

TRIVIÑOS, Augusto Nibaldo Silva. Introdução à pesquisa em ciências sociais: a pesquisa qualitativa em Educação. São Paulo: Atlas, 1987.
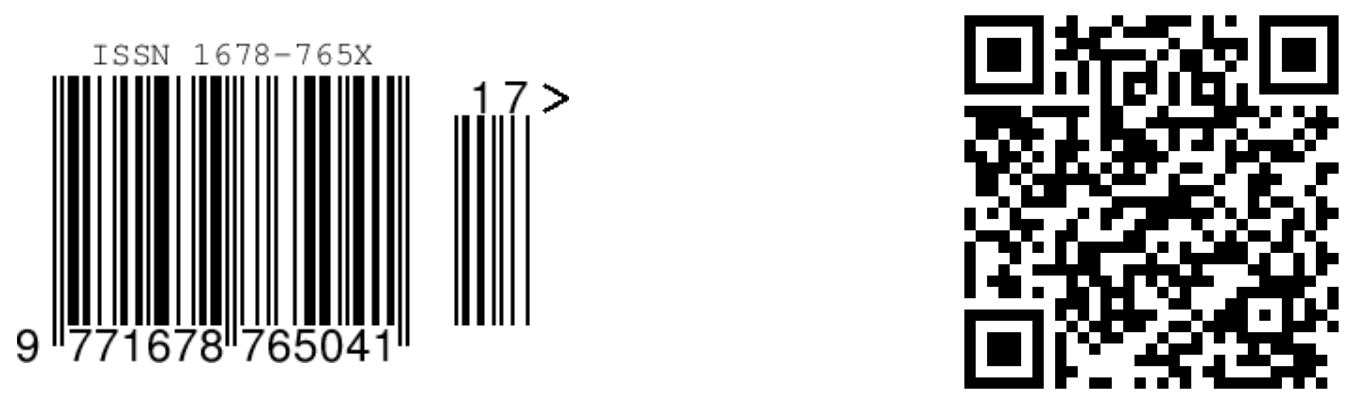